\title{
Ki67 Labelling Index predicts clinical outcome and survival in oral squamous cell carcinoma
}

\section{Abstract}

Amol Ramchandra GADBAIL

Sachin C. SARODE ${ }^{2}$

Minal S. CHAUDHARY ${ }^{3}$

Shailesh M. GONDIVKAR ${ }^{4}$

Satyajit Ashok TEKADE ${ }^{5}$

Monal YUWANATI ${ }^{6}$

Shankargouda PATIL ${ }^{7}$
Submitted: September 12, 2020

Modification: November 3, 2020

Accept: November 19, 2020
Objective: To investigate the Ki 67 expression and its correlation with clinicopathological features and 3 years as well as 5 years survival rate in oral squamous cell carcinoma (OSCC). Methodology: Total 217cases of OSCC primarily treated with surgery with or without radiation were included. All patients were followed up for 3 years and 150 were followed up of 5 years for disease free survival. The immunohistochemistry was carried out on neutral buffered formalin fixed paraffin embedded tissue to evaluate the expression of Ki67. Results: The Ki67 labeling index (LI) was significantly higher with respect to adverse clinicopathological parameters such as histopathological grading $(p<0.001)$, clinical TNM staging $(p<0.001)$ and nodal metastasis $(p<0.001)$. The OSCC patients survived for less than 3 and 5 years were showed significantly higher Ki67 LI as compared to diseases free survived more than 3 and 5 years $(p<0.001)$. The three years survival rate of OSCC patient significantly higher with low Ki67 LI ( $\leq 45) 96.2 \%$, followed by moderate Ki67 LI (46 to 60) 60.7\% and high Ki67 LI ( $\geq 61$ ) 37.7\% ( $<<0.001$ ). The five years survival rate of OSCC patient statistically significantly higher with low Ki67 LI ( $\leq 45$ )93.3\%, followed by moderate Ki67 LI (46 to 60) 46.8\% and Ki67 LI ( $\geq 61$ ) 23.3\% ( $p<0.001)$. Conclusion: The measurement of cell proliferative activity by using Ki67 antigen expression in individual OSCC might provide unique, predictive information on clinical outcome, prognosis and deciding treatment modalities in OSCC.

Keywords: Oral Squamous Cell Carcinoma. Ki67 Labelling Index. Proliferation. Prognosis. Survival.
Corresponding address: Dr. Amol Ramchandra Gadbail Indira Gandhi Government Medical College and Hospital - Department of Dentistry Nagpur - Maharashtra - India. Phone: +919766135691 e-mail: gadbail@yahoo.co.in
${ }^{1}$ Indira Gandhi Government Medical College and Hospital, Department of Dentistry, Nagpur, Maharashtra, India.

${ }^{2}$ Dr. D.Y. Patil Dental College and Hospital, Dr. D.Y. Patil Vidyapeeth, Sant-Tukaram Nagar, Department of Oral Pathology and Microbiology, Pimpri, India

${ }^{3}$ Datta Meghe Institute of Medical Sciences, Sharad Pawar Dental College \& Hospital, Department of Oral Pathology and Microbiology, Sawangi (M), Wardha, Maharashtra, India.

${ }^{4}$ Government Dental College \& Hospital, Department of Oral Medicine and Radiology, Nagpur, Maharashtra, India.

${ }^{5}$ Modern Dental College \& Research Centre, Department of Oral Pathology and Microbiology, Gandhi Nagar, Indore, Madhya Pradesh 453112, India.

${ }^{6}$ People's University, People's College of Dental Science \& Research Centre, Department of Oral Pathology and Microbiology, Bhopal, Madhya Pradesh, India.

${ }^{7}$ Jazan University, College of Dentistry, Division of Oral Pathology, Department of Maxillofacial Surgery and Diagnostic Sciences, Jazan, Saudi Arabia.

*This original study was carried out at Department of Oral and Maxillofacial Pathology and Microbiology, Sharad Pawar Dental College and Hospital, Sawangi (M), Wardha, Maharashtra, India. 


\section{Introduction}

Globally, oral squamous cell carcinoma (OSCC) incidence is 2.7 in 100000 populations. In southcentral Asia, the incidence of OSCC cases was highest that is $40.9 \%$ of all incident cases of OSCC and often associated poor prognosis due to high morbidity and mortality rate. ${ }^{1} \mathrm{OSCC}$ is extensively investigated for identification and validation of prognostic and predictive markers. However, up until this point, no single marker is consistently acknowledged for routine clinical use in OSCC patients. ${ }^{2}$

Cell proliferation is viewed as a key fundamental biological process in the growth and development as well as upkeep of homeostasis of tissue. The biological behavior of tumor such as local invasion/ expansion, local recurrence, metastatic potential as well as disease free survival is predicted by assessment of cell proliferation in histopathology by means of immunohistochemical evaluation. ${ }^{3}$ Thus, evaluation of proliferative status is conventionally viewed as helpful tool in deciding the biological aggressiveness of any tumor.

$\mathrm{Ki67}$ is a large non-histone protein present in the nucleus and nucleolar region, which is seen in cells undergoingproliferation. ${ }^{4} \mathrm{Ki} 67$ antigen expression is a reliable and potent biomarker for the accurate, simple and prompt identification of the fraction of cells with proliferative potential in a tumor. ${ }^{5}$ Higher Ki67 expression is an indicator of tumor cells with higher proliferation and locally invasive potential and thus providing one of the best markers for the evaluation of biological aggressiveness of tumor. ${ }^{6}$

Ki67 expression has been accounted to provide a diagnostic and poor prognostic biomarker for OSCC patients. ${ }^{7-9}$ Despite several efforts made in the literature, still there is a controversy existed for $\mathrm{Ki}-67$ being utilized as the proliferation capacity of cancer cells as a predictive biomarker for tumor grade, nodal metastasis, clinical TNM stage and survival rate. Xie, et al. ${ }^{10}$ (2016) carried out meta-analysis on prognostic implication of $\mathrm{Ki}-67$ expression in OSCC and recommended further studies on $\mathrm{Ki} 67$ expression with five-year survival rate by using standardized immunohistochemistry protocols needed to further strengthen its role as diagnostic and prognostic predictive marker.

Looking at the mandate of five-year survival analysis, the present study was designed to investigate immunohistochemical expression of $\mathrm{Ki} 67$ in OSCC with primary focus on three as well as five years survival rate and to assess its predictive value on clinical outcome. These new objectives were investigated on the samples, which were utilized in our previously published papers. ${ }^{11,12}$

\section{Methodology}

The present study was conducted at the Sharad Pawar Dental College and Hospital, Wardha, Maharashtra, India. Institutional ethics committee of Datta Meghe Institute of Medical Sciences, Deemed to be University, Wardha, India was granted the ethical approval for the present study (Ref no. DMIMS (DU)/IEC/2014-15/953, dated 15/12/2014).The written consent was obtained from the patient, who participated in this study.

The study population was retrieved from year 2010 to 2015, which was previously utilized for our research publications ${ }^{11,12}$ with different objectives. The clinically diagnosed and histologically confirmed 217 cases of OSCC, who fulfilled inclusion and exclusion criteria's, were included. All retrieved cases were primarily treated with wide local surgical excision with normal margins and cervical neck dissection with or without radiation. Patients with coexisting malignancy, previous history of oropharyngeal or oral or any other head and neck cancer, recurrent or distant disease, any other systemic diseases, and preoperative chemotherapy, radiotherapy, or surgery were excluded from the study. Dissected cervical lymph nodes obtained from surgically excised specimens were examined histopathologically for confirmation of lymph node metastasis. The clinical TNM staging of all OSCC patients were done by using the American Joint Committee of Cancer $^{13}$ clinical TNM staging system for oral and oropharyngeal cancer. The clinical TNM staging was further broadly categories for OSCC cases into early clinical TNM stage (I and II) and advanced clinical TNM stage (III and IV). Demographic details along with clinical features, relevant habit history, and operative details were obtained. Disease free survival of 3 years as well as for some cases 5 years was recorded on follow up.

\section{Study design}

As recommended by Dissanayake, et al. ${ }^{14}$ (2003) 
neoplastic cells from invasive tumor front region are more informative in studying cell proliferation markers. The histopathological slides of incisional biopsy as well as from resected specimen of OSCC were examined by three oral pathologists independently and those sections showing invasive tumor front of OSCC were utilized for immunohistochemical evaluation of Ki67 antigen expression. All the hematoxylin and eosin stained histopathology and IHC (Ki67) slides were blinded for microscopic analysis. All the included cases were confirmed for histopathological diagnosis of squamous cell carcinoma and were classified in to well-differentiated SCC (WDSCC), moderatelydifferentiated SCC (MDSCC) and poorly-differentiated SCC (PDSCC). Similarly, three oral pathologists, who were blinded for histopathological grading status of OSCC cases, were independently performed IHC scoring of Ki67. The obtained IHC score for Ki67 were then computed for all OSCC.

\section{Immunohistochemistry}

The standard procedure of immunohistochemistry (IHC) was done for Ki67, by utilizing appropriate controls on neutral buffered formalin fixed paraffin embedded tissue. The tissue sections were treated with $01 \mathrm{~mol} / \mathrm{L}$ sodium citrate buffer $(\mathrm{pH} \mathrm{6.0)}$ in microwave oven for 10 minute followed by bench-cooled for 20 min, and again the same cycle was repeated for the antigen retrieval. Endogenous peroxidase activities of the tissue were blocked by incubating the tissue sections with $3 \% \mathrm{H} 2 \mathrm{O} 2$ in methanol for 30 minutes. The non-specific tissue reactions were prevented by incubating the tissue sections with $10 \%$ serum for 10 minutes. For IHC detection of Ki67 antigen, pre-diluted Monoclonal Mouse Anti-Human, Ki67 antibody [clone MIB-1; Product code:N1633; Dako, Denmark (DD)], was incubated with tissue sections at room temperature in a humidifying chamber for 60 minutes. Known hyperplastic lymph node was used as a positive control for $\mathrm{Ki}-67$. One section from positive control was used as the negative control by omitting the primary antibody and by incubating with serum. The horseradish peroxidase labeled polymer anti-mouse secondary antibody (DakoEnVision System, Product code:K4000, DD) against the primary antibody was incubated at room temperature in humidifying chamber for 30 minutes. To visualized Ki67 antigen antibody complex (expression), the freshly prepared substrate/chromogen solution of 3 ,
30 Diaminobenzidine (DAB) in provided buffer was used and counterstained in Mayer's hematoxylin. ${ }^{15}$ The brown coloration of nucleus indicates the positivity for Ki67 antigen expression, where as the blue color of nucleus due to counterstained in Mayer's hematoxylin indicates the Ki67 negative cells.

\section{Immunohistochemistry scoring}

Neoplastic epithelial cells were viewed as positive for the Ki67 antigen expression, if intranuclear DAB staining (brown color) was observed. Every single stained nuclei were counted positive irrespective of intensity of staining. Invasive tumor front areas as well as areas with highest density of Ki67 labeled neoplastic epithelial cells were located by screening the IHC sections at a $100 \mathrm{X}$ magnification by Leica DM LB2 microscope. In the most heavily Ki67 labeled areas, Ki67 positive neoplastic epithelial cell counts were carried outin 5 randomly selected fields at $400 \mathrm{X}$ magnification. Minimum of $1000 \mathrm{Ki} 67$ labeled neoplastic epithelial cells were counted in each section. The number of positively stained nuclei was measured as a percentage of the total number counted neoplastic epithelial cells. Ki67 labeling index (LI) was derived as number positive cells for Ki67 multiplied by 100 and divided by total number observed neoplastic epithelial cells. Based on median and also considering the frequency distribution KI67 LI, cut off values for KI67 LI were generated for three groups to avoid the formation of very small and too many groups. ${ }^{9}$ Thus, based on the KI67 LI, the Ki67 expression were categorized in to low: Ki67 LI $\leq 45$, moderate: Ki67 LI 46 to 60 and high: Ki67 LI $\geq 61$.

\section{Statistical analysis}

The data were statistically analyzed using SPSS, version 17.0 for Windows. One-way ANOVA and Tukey's HSD test were utilized to find out the differences of Ki67 LI amongst the various histopathological grades, clinical TNM stage, and sites of OSCC. Independent student $\mathrm{t}$ test was applied to find out the differences of KI67 LI between metastatic and non-metastatic, early and advanced clinical TNM stage, survived and not survived less than 3 year, and survived and not survived less than 5 years. KaplanMeier survival curves as well as the longrank test were used to estimate and compare disease free 3 and 5 years survival with low, moderate and high Ki67 LI. The level of statistical significance was at $p<0.05$. 


\section{Results}

\section{Details of demographic and clinicopathological features of oral squamous cell carcinoma}

Total 217 OSCC patients were included in this study, who were fulfilled the inclusion and exclusion criteria. OSCC cases were predominantly seen in males 159 (73.27\%) with male to female $35(26.72 \%)$ ratio was 4.54:1. The age of OSCC patients were ranges from 20 years to 79 years and the mean age of OSCC patient was $50.25( \pm 12.14)$ years. The most common site for OSCC was buccal mucosa $84(38.70 \%)$ followed by gingivobuccal sulcus $69(31.79 \%)$, tongue 24 $(11.05 \%)$, retromolar region $16(7.37 \%)$, labial
Mucosa $11(5.06 \%)$, palate $10(4.60 \%)$ and floor of mouth $3(1.38 \%)$. Tobacco lime and betel nut (TLB) $135(62.21 \%)$ was the most common habit noted in OSCC patient followed by tobacco lime (TL) 45 $(20.73 \%)$ and Betel nut (BN) 33 (15.20\%). Nearly 95\% cases of OSCC were MDSCC 106 (48.84\%) and WDSCC 100 (46.08\%). MDSCC were the most common histopathological type of OSCC. PDSCC were found in 11 (5.06\%) cases of OSCC. Clinical TNM stage IV was the most commonly observed in 94 (43.31\%) OSCC followed by Stage III 55 (25.34\%) to stage II 52 (23.96\%) and stage I 16 (7.37\%). Advanced clinical TNM stage was observed in 149 (68.66\%) OSCC and early clinical TNM stage was observed in 68

Table 1- Details of demographic and clinicopathological parameters of oral squamous cell carcinoma patients

\begin{tabular}{|c|c|c|}
\hline \multicolumn{2}{|c|}{ Characteristics } & \multirow{2}{*}{$\begin{array}{c}\text { OscC }(\mathbf{n}=\mathbf{2 1 7}) \\
50.25( \pm 12.14)\end{array}$} \\
\hline \multirow{2}{*}{ Age } & Mean (SD) & \\
\hline & Range & $20-79$ \\
\hline \multirow{2}{*}{ Gender } & Male & $159(73.27 \%)$ \\
\hline & Female & $35(26.72 \%)$ \\
\hline \multirow{7}{*}{ Site } & Buccal Mucosa & $84(38.70 \%)$ \\
\hline & Gingivo-buccal Sulcus & $69(31.79 \%)$ \\
\hline & Tongue & $24(11.05 \%)$ \\
\hline & Retromaolar & $16(7.37 \%)$ \\
\hline & Palate & $10(4.60 \%)$ \\
\hline & Labial Mucosa & $11(5.06 \%)$ \\
\hline & Floor of Mouth & $3(1.38 \%)$ \\
\hline \multirow{3}{*}{ Histopathological diagnosis } & WDSCC & $100(46.08 \%)$ \\
\hline & MDSCC & $106(48.84 \%)$ \\
\hline & PDSCC & $11(5.06 \%)$ \\
\hline \multirow{4}{*}{ Habits } & Tobacco and lime & $45(20.73 \%)$ \\
\hline & Tobacco lime and Betel nut & $135(62.21 \%)$ \\
\hline & Betel nut & $33(15.20 \%)$ \\
\hline & No habits & $4(1.84 \%)$ \\
\hline \multirow{4}{*}{ Clinical TNM Stage } & Stage I & $16(7.37 \%)$ \\
\hline & Stage II & $52(23.96 \%)$ \\
\hline & Stage III & $55(25.34 \%)$ \\
\hline & Stage IV & $94(43.31 \%)$ \\
\hline \multirow{2}{*}{ Clinical TNM Stage } & Early Stage & $68(31.33 \%)$ \\
\hline & Advanced Stage & $149(68.66 \%)$ \\
\hline \multirow{2}{*}{ Metastasis } & Non-meta & $141(64.97 \%)$ \\
\hline & Metastatic & $76(35.02 \%)$ \\
\hline \multirow{2}{*}{3 years disease free survival $(n=217)$} & Non-survived & $69(31.79 \%)$ \\
\hline & Survived & $148(68.20 \%)$ \\
\hline \multirow{2}{*}{5 years disease free survival $(n=150)$} & Non-survived & $69(46.00 \%)$ \\
\hline & Survived & $81(54.00 \%)$ \\
\hline
\end{tabular}

Note:- OSCC: Oral squamous cell carcinoma, WDSCC: Well differentiated squamous cell carcinoma, MDSCC: Moderately differentiated squamous cell carcinoma, PDSCC: Poorly differentiated squamous cell carcinoma, SD: standard deviation, TNM: Tumor (T) Nodes (N) and Metastasis (M). 
(31.33\%) OSCC. The cervical lymph node metastasis was found in 68 (31.33\%) OSCC cases. All 217 cases were followed up for 3 years and $148(68.20 \%)$ cases of OSCC were survived. A five year follow up data of 150 cases were available and 81 (54.00\%) OSCC cases found to be survived (Table 1 ).

\section{Association of Ki67 LI with clinicopathological parameters of oral squamous cell carcinoma}

Statistically significant variations of mean Ki67 LI were found among all groups of OSCC $(p<0.001)$. Ki67 LI were observed statistically significantly in ascending order from WDSCC 43.72 ( \pm 5.28 ) to MDSCC 59.41 $( \pm 9.75)$ to PDSCC $74.59( \pm 9.20)(p<0.001)$ (Figure 1) (Table 2).

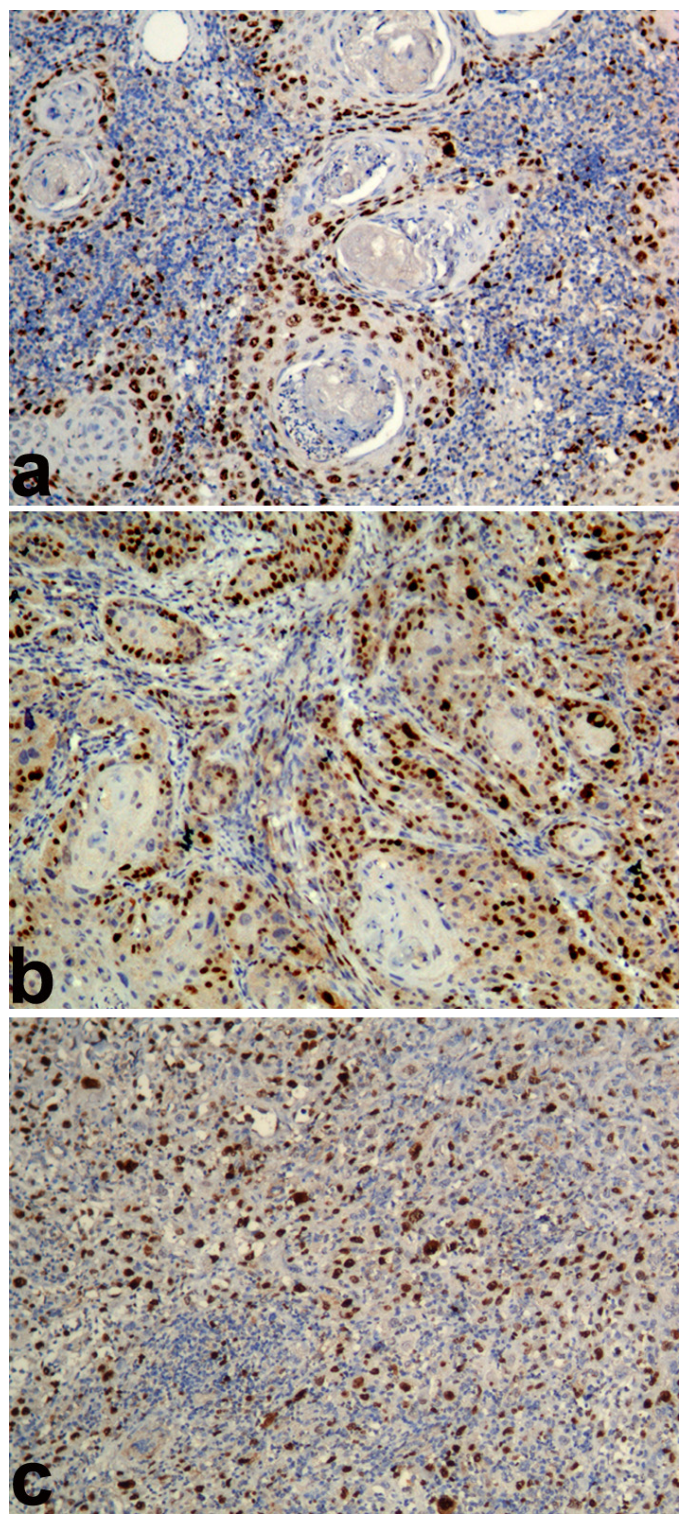

Figure 1- Photomicrograph showing Ki67 antigen expression (Ki67 labeling index) in a) Well differentiated squamous cell carcinoma, b) Moderately differentiated squamous cell carcinoma, c) Poorly Moderately differentiated squamous cell carcinoma (Immunohistochemistry; Magnification X100)
Statistically significant variations of mean Ki67 LI were found among clinical TNM Stage I, Stage II, Stage III, and Stage IV of OSCC $(p<0.001)$. There was statistical significant difference for Ki67 LI observed between Stage III $51.83( \pm 10.15)$ and Stage IV 57.17 $( \pm 11.71)(p=0.034)$; Stage I $46.54( \pm 9.35)$ and Stage IV $57.17( \pm 11.71)(p=0.004)$; Stage II 48.47 $( \pm 12.99)$ and Stage IV $57.17( \pm 11.71)(p<0.001)$. The mean of Ki67 LI were statistically significantly higher in Advanced TNM stage55.20 ( \pm 11.42$)$ as compared to Early Stage48.01 $( \pm 12.19)$ of OSCC $(p<0.001)$ (Table 2).

There was no statistical significant variations of mean of Ki67 LI found among various sites of OSCC $(P=0.374)$. However, the Ki67 LI was marginally higher in Palate $56.28( \pm 13.89)$ followed by Floor of mouth 55.28 ( \pm 15.09$)$, Retromolar 55.89 ( \pm 6.64 ), Gingivo-buccal Sulcus 53.74 ( \pm 11.82$)$, Tongue 53.50 ( \pm 14.43$)$, Buccal Mucosa $52.04( \pm 12.34)$ and Labial Mucosa $45.79( \pm 9.66)$ (Table 2).

The mean of Ki67 LI were statistically significantly higher in Metastatic $60.23( \pm 10.99)$ as compared to non-metastatic $49.03( \pm 10.83)$ cases of OSCC $(p<0.001)$.

\section{The relationship between Ki67 LI with 3 and 5 years disease free survival of oral squamous cell carcinoma patients}

On 3 years of follow up of for disease free survival, the mean of Ki67 LI were statistically significantly higher in Non-survived $60.82( \pm 10.64)$ as compared to survived cases 49.28 ( \pm 10.97 ) of OSCC ( $<<0.001)$. Similarly on 5 years of follow up of for disease free survival, the mean of Ki67 LI were statistically significantly higher in Non-survived $60.82( \pm 10.64)$ as compared to survived cases $49.25( \pm 10.20)$ of OSCC $(p<0.001)$ (Table 2).

The three years survival rate of OSCC patient statistically significantly higher with Ki67 LI $\leq 45(96.2 \%)$, followed by Ki67 LI of 46 to 60 (60.7\%) and Ki67 LI of $\geq 61(37.7 \%) \quad(p<0.001)$ (Figure 2$)$ (Figure 3). The five years survival rate of OSCC patient statistically significantly higher with Ki67 LI of $\leq 45$ (93.3\%), followed by Ki67 LI of 46 to 60 (46.8\%) and Ki67 LI of $\geq 61(23.3 \%)(p<0.001)$ (Figure 4) (Table 3). 
Table 2- Comparative analysis of Ki67 labeling index in clinicopathological and survival of all Oral squamous cell carcinoma

\begin{tabular}{|c|c|c|c|c|c|}
\hline Parameters & Groups & $\mathbf{N}$ & Mean & Sta. Dev. & $\begin{array}{c}\text { Tukey HSD test/ Independent } \\
\text { Samples T Test }\end{array}$ \\
\hline \multirow{3}{*}{$\begin{array}{l}\text { Histopathological } \\
\text { Grading }\end{array}$} & $\operatorname{WDSCC}(\mathrm{A})$ & 100 & 43,72 & 5,28 & \multirow{3}{*}{$A<B<C \quad P<0.001$} \\
\hline & MDSCC (B) & 106 & 59,41 & 9,75 & \\
\hline & $\operatorname{PDSCC}(C)$ & 11 & 74,59 & 9,2 & \\
\hline \multirow{6}{*}{ TNM Stage } & Stage I (A) & 16 & 46,54 & 9,35 & \multirow{4}{*}{$\begin{array}{l}A<B(p=0.936) ; \\
B<C(p=0.433) \\
A<C(p=0.370) \\
C<D(p=0.034) \\
A<D(p=0.004) \\
B<D(p<0.001)\end{array}$} \\
\hline & Stage II (B) & 52 & 48,47 & 12,99 & \\
\hline & Stage III (C) & 55 & 51,83 & 10,15 & \\
\hline & Stage IV (D) & 94 & 57,17 & 11,71 & \\
\hline & Early Stage & 68 & 48,01 & 12,19 & \multirow{2}{*}{$P<0.001$} \\
\hline & Advanced Stage & 149 & 55,2 & 11,42 & \\
\hline \multirow{2}{*}{$\begin{array}{l}\text { Cervical lymph node } \\
\text { metastasis }\end{array}$} & Non-metastatic & 141 & 49,03 & 10,83 & \multirow{2}{*}{$P<0.001$} \\
\hline & Metastatic & 76 & 60,23 & 10,99 & \\
\hline \multirow[t]{2}{*}{$\begin{array}{l}3 \text { years disease free } \\
\text { survival }(n=217)\end{array}$} & Non-survived & 69 & 60,82 & 10,64 & \multirow[t]{2}{*}{$P<0.001$} \\
\hline & Survived & 148 & 49,28 & 10,97 & \\
\hline \multirow{2}{*}{$\begin{array}{l}5 \text { years disease free } \\
\text { survival }(n=150)\end{array}$} & Non-survived & 69 & 60,82 & 10,64 & \multirow{2}{*}{$P<0.001$} \\
\hline & Survived & 80 & 49,25 & 10,2 & \\
\hline \multirow{7}{*}{ Site } & Buccal Mucosa & 84 & 52,04 & 12,34 & \multirow{7}{*}{$\begin{array}{c}\text { One-Way ANOVA } \\
P=0.374\end{array}$} \\
\hline & GB Sulcus & 69 & 53,74 & 11,82 & \\
\hline & Tongue & 24 & 53,5 & 14,43 & \\
\hline & Retromolar & 16 & 55,89 & 6,64 & \\
\hline & Palate & 10 & 56,28 & 13,89 & \\
\hline & Labial Mucosa & 11 & 45,79 & 9,66 & \\
\hline & Floor of Mouth & 3 & 55,28 & 15,09 & \\
\hline
\end{tabular}

Note:- OSCC: Oral squamous cell carcinoma, WDSCC: Well differentiated squamous cell carcinoma, MDSCC: Moderately differentiated squamous cell carcinoma, PDSCC: Poorly differentiated squamous cell carcinoma, TNM: Tumor (T) Nodes (N) and Metastasis (M).

\section{Discussion}

OSCC is an aggressive neoplasm with unpredictable biological behavior. This results in unfavorable prognosis leading to functional impairment as well as high mortality rate irrespective of type of treatment modality rendered. ${ }^{16}$ Treatment modalities and prognosis for OSCC were routinely determined based on clinical features such as tumor size, cervical metastasis to lymph node, distant metastasis and histopathological features mainly histological grade with other characteristics such as mitotic activity, vascular or perineural invasion. ${ }^{17}$ Recently, numerous studies observed that the clinico pathological factors such as advanced age, lymph node metastasis, advanced TNM stage, advanced histopathological grade, the presence of perineural invasion, vascular invasion, tumour-stroma ratio (TSR) and tumour budding were predicator of poor survival in OSCC patients. ${ }^{18-22}$ Despite of their claimed usefulness in various studies, characterization of OSCC that are at higher risk for recurrence and relapse is major concern. However, use of cost effective, easy and widely use immunohistochemistry to assess molecular markers leads to an increased understanding of biological behavior of OSSC. With the use of molecular markers predicting biological aggressiveness, locoregional recurrence and survival are useful in identification of patients, who needs more individualized intensive treatment regimes such as chemotherapy and radiotherapy in addition to surgery. An increasing number of studies, have revealed that Ki67 as a reliable cell proliferation biomarker was unregulated in numerous tumors and may be used as an important factor in cancer grading and prognostic evaluation. ${ }^{23}$ Thus, in this study we evaluated Ki67 expression in invasive front region of OSCC with a lager cohort of 217 cases and $\mathrm{K} 67$ expression was also correlated with clinical outcome and three as well as five years disease free survival.

In this study, we assess the cut of range value for $\mathrm{Ki} 67 \mathrm{LI}$ as low, moderate and high with respect to three 


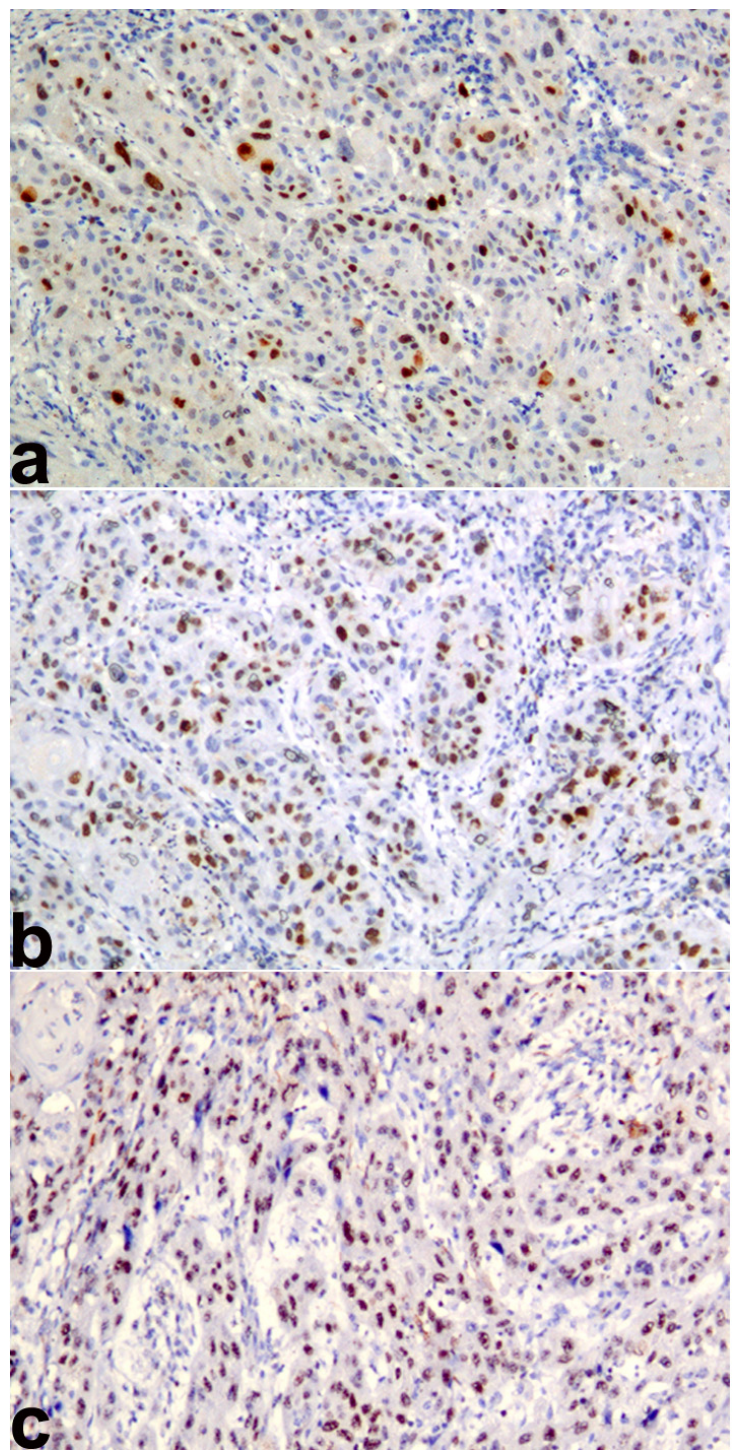

Figure 2- Photomicrograph showing Ki67 antigen expression (Ki67 labeling index) in oral squamous cell carcinoma a) Low Ki67 labeling index ( $\leq 45)$, b) Moderate Ki67 labeling index (46 to 60 ) and c) High Ki67 labeling index $(\geq 61)$. (Immunohistochemistry; Magnification X100)

and five years disease free survival of OSCC patients. The three year disease free survival rate of OSCC patient significantly higher with low Ki67 LI (96.2\%), followed by moderate KI67 LI (60.7\%) and high Ki67 LI (37.7\%). The five year disease free survival rate of OSCC patient significantly higher with low Ki67 LI (93.3\%), followed by moderate Ki67 LI (46.8\%) and high Ki67 LI (23.3\%). In this study for the first time we introduce the range value for ki67 LI in OSCC that could be use as prognostic indicator for survival and to decide the treatment regime.

The mean of Ki-67 LI, was significantly higher in OSCC patients survived for less than 3 years as compared to diseases free survived OSCC patients more than 3 years. Similarly, the mean of Ki-67 LI, was significantly higher in OSCC patients survived for less than 5 years as compared to diseases free survived OSCC patients more than 5 years. It has been noticed in previous studies ${ }^{9,24-26}$ that $\mathrm{K} 67$ expression in OSCC was identified as prognostic factor for survival rate. However, several other studies ${ }^{27-30}$ have described no association between higher cell proliferation and survival. Recently, Jing, et al. ${ }^{9}$ (2019) studied Ki67 expression in large cohort of 298 OSCC and found that Ki67 expression was independent prognostic marker in OSCC patients. Ki67 expression was also found to be prognostic marker in oropharyngeal and OSCC with a lager cohort of 239 cases. ${ }^{26}$ Therefore, it is summarize that the increase in $\mathrm{Ki} 67$ expression associated with a poor prognosis of OSCC. It was also suggested that $\mathrm{Ki67}$ is an indicator for treatment failure in OSCC. ${ }^{9,26}$ Thus, it was further strengthen that the high cell proliferation identified by Ki67 antigen expression is a reliable prognostic marker in oral cancer.

In this study, a significant increase in Ki-67 LI was observed from WDSCC to MDSCC to PDSCC. This results was in agreement with previous studies ${ }^{9,31-35}$ and revealed that as the Ki67 LI increases with poorer the degree of tumor cell differentiation. In contrast, few studies ${ }^{29,36}$ failed to show correlation of Ki67 LI and degree of differentiation. Disparity in the methodology, assessment of Ki67 immunoreactivity, and sample size may result in these conflicting results. Higher expression of $\mathrm{Ki} 67$ protein was discovered in undifferentiated/poorly differentiated squamous cells carcinoma. Therefore, results of the present study further strengthen the fact that, the Ki67 LI could be considered as useful potential biomarker in grading the OSCC.

The mean of Ki-67 LI was significantly higher in metastatic as compared to non-metastatic OSCC. Other studies 3,25,32,36 found insignificant correlation with cell proliferation and cervical lymph node metastasis, which are not in accordance with this study results. In this study large cohort of OSCC was used and results are in accordance with previous studies. 9,28,33,37,38 This finding may implicate that tumors with high cell proliferation index may point out towards aggressive behavior of a tumour and a potential for metastasis.

In the present study, Ki67 LI was significantly higher in TNM stage IV as compared to stage III. However, non-significant difference of ki67 LI was found amongst stage I, stage II and stage III. The previous studies $3,30,32,34,36$ showed no significant association between Ki67LI and clinical TNM staging. 


\section{Survival Functions}

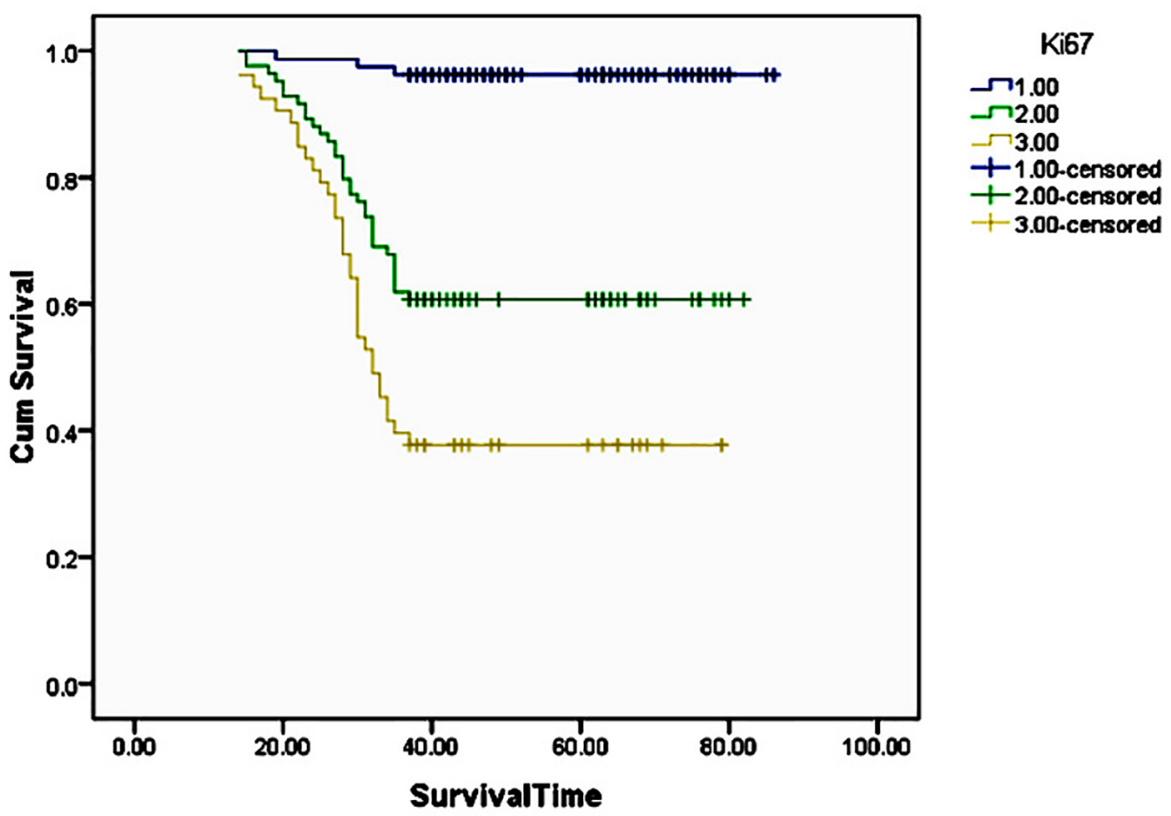

Figure 3- The Kaplan-Meier curve for 3 years disease free survival rate for oral squamous cell carcinoma with respect to 1: Low Ki67 labeling index ( $\leq 45)$, 2: Moderate Ki67 labeling index (46 to 60) and 3: High Ki67 labeling index ( $\geq 61)$

\section{Survival Functions}
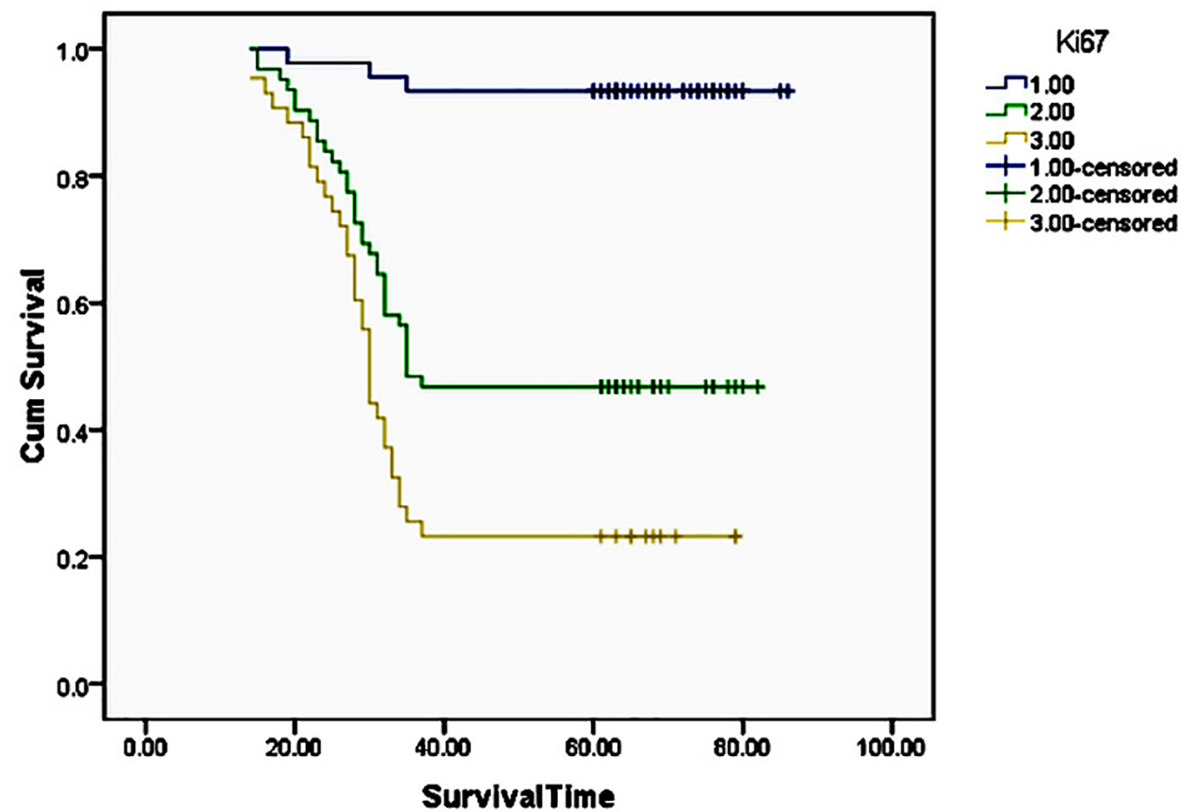

Figure 4- The Kaplan-Meier curve for 5 years disease free survival rate for oral squamous cell carcinoma with respect to 1 : Low Ki67 labeling index (s45), 2: Moderate Ki67 labeling index (46 to 60) and 3: High Ki67 labeling index ( $\geq 61$ )

Interestingly, on broadly categories TNM staging, the mean Ki67 LI was significantly higher in advanced stage OSCC as compared to early stage OSCC. These findings are in agreement with previous studies ${ }^{28,33}$ suggesting that the increased Ki67 LI indicates the higher intrinsic growth potential of the tumor resulting in advance TNM staging.

In accordance with previous studies ${ }^{37,38}$ the result of this study have also showed non-significant difference of Ki67 LI amongst site of OSCC.

In this study the Ki67 LI was significantly higher with respect to adverse clinicopathological parameters such as histopathological grading, clinical TNM staging, cervical lymph node metastasis and 3 as well as 5 years disease free survival of OSCC. Thus, it can be suggested that assessment of cell 
Table 3- Kaplan Meier Survival analysis: Ki67 labeling index and 3 years and 5 years survival analysis of oral squamous cell carcinoma

\begin{tabular}{|c|c|c|c|c|c|c|c|}
\hline Survival & $\begin{array}{l}\text { Ki67 labeling } \\
\text { index }\end{array}$ & $\mathbf{N}$ & $\begin{array}{l}\text { Deaths } \\
\text { (N) }\end{array}$ & Survived (N) & $\begin{array}{c}\text { Log Rank } \\
\text { (Mantel-Cox) }\end{array}$ & $\begin{array}{c}\text { Breslow } \\
\text { (Generalized } \\
\text { Wilcoxon) }\end{array}$ & Tarone-Ware \\
\hline \multirow{4}{*}{$\begin{array}{l}3 \text { years disease free } \\
\text { survival }(n=217)\end{array}$} & Low $(\leq 45)$ & 80 & 3 & 77 (96.2\%) & \multirow{4}{*}{$\begin{array}{c}\text { Chi-Square = } \\
55.72 ; \\
P<0.001\end{array}$} & \multirow{4}{*}{$\begin{array}{c}\text { Chi-Square = } \\
53.86 \\
P<0.001\end{array}$} & \multirow{4}{*}{$\begin{array}{c}\text { Chi-Square = } \\
54.93 \\
\mathrm{P}<0.001\end{array}$} \\
\hline & $\begin{array}{l}\text { Moderate (46 } \\
\text { to } 60)\end{array}$ & 84 & 33 & $51(60.7 \%)$ & & & \\
\hline & High ( $\geq 61)$ & 53 & 33 & $20(37.7 \%)$ & & & \\
\hline & Overall & 217 & 69 & $148(68.2 \%)$ & & & \\
\hline \multirow{4}{*}{$\begin{array}{l}5 \text { years disease free } \\
\text { survival }(n=150)\end{array}$} & Low $(\leq 45)$ & 45 & 3 & $42(93.3 \%)$ & \multirow{4}{*}{$\begin{array}{c}\text { Chi-Square = } \\
44.94 \\
\mathrm{P}<0.001\end{array}$} & \multirow{4}{*}{$\begin{array}{c}\text { Chi-Square = } \\
41.38 \\
\mathrm{P}<0.001\end{array}$} & \multirow{4}{*}{$\begin{array}{c}\text { Chi-Square = } \\
43.38 \\
\mathrm{P}<0.001\end{array}$} \\
\hline & $\begin{array}{l}\text { Moderate (46 } \\
\text { to } 60)\end{array}$ & 62 & 33 & $29(46.8 \%)$ & & & \\
\hline & High $(\geq 61)$ & 43 & 33 & $10(23.3 \%)$ & & & \\
\hline & Overall & 150 & 69 & $81(54.0 \%)$ & & & \\
\hline
\end{tabular}

proliferative activity by quantitative measurement of Ki67 positive neoplastic epithelial cells in individual invasive OSCC, may thus reveal unique, predictive information on clinical outcome, prognosis and deciding treatment modalities. Nevertheless, taking into consideration the extensive heterogeneity of tumors, it is recommended further research with standardized uniform immunohistochemistry protocol for Ki67 expression and large cohort of OSCC with 5 to 10 years follow up data to validate the range of Ki67LI for prognosis and treatment outcome.

\section{Conflict of interest}

All the authors associated with present manuscript declared no potential conflicts of interest.

\section{Funding source}

The author received no specific funding for this work.

\section{Acknowledgement}

We would like to thank authorities of SharadPawar Dental College and Hospital, Sawangi (Meghe), Wardha for providing the infrastructure and related resources that immensely helped in execution of the present study. We also acknowledge that the samples and marker used in the present paper were taken from our already published work (cited in the paper). However, the objectives of the present study are totally different and are not related to our previously published work.

\section{Authors' contributions}

Gadbail, Amol R: Conceptualization (Lead); Data curation (Equal); Formal analysis (Equal); Investigation (Lead); Methodology (Equal); Writingoriginal draft (Equal). Sarode, Sachin: Investigation
(Lead); Writing-original draft (Lead). Chaudhari, Minal S: Resources (Lead); Supervision (Lead); Validation (Equal); Visualization (Equal). Gondivkar, SM: Formal analysis (Equal); Writing-original draft (Lead). Tekade, Satyajit A: Formal analysis (Equal); Investigation (Equal); Methodology (Lead). Yuwanati, MB: Software (Lead); Validation (Lead); Visualization (Lead). Patil, Shankargouda: Visualization (Lead); Writing-review \& editing (Lead)

\section{Reference}

1- Pimenta Amaral TM, Silva Freire AR, Carvalho AL, Pinto CA, Kowalski LP. Predictive factors of occult metastasis and prognosis of clinical stages I and II squamous cell carcinoma of the tongue and floor of the mouth. Oral Oncol. 2004;40(8):780-6. doi:10.1016/j. oraloncology.2003.10.009

2- Kim KY, McShane LM, Conley BA. Designing biomarker studies for head and neck cancer. Head Neck. 2014;36(7):1069-75. doi:10.1002/ hed. 23444

3- Watanabe S, Watanabe R, Oton-Leite AF, et al. Analysis of cell proliferation and pattern of invasion in oral squamous cell carcinoma. J Oral Sci. 2010;52(3):417-24. doi:10.2334/josnusd.52.417

4- Gerdes J, Lemke $H$, Baisch $H$, Wacker $H H$, Schwab U, Stein $H$. Cell cycle analysis of a cell proliferation-associated human nuclear antigen defined by the monoclonal antibody Ki-67. J Immunol. 1984;133(4):1710-5.

5- Whitfield ML, George LK, Grant GD, Perou CM. Common markers of proliferation. Nat Rev Cancer. 2006;6(2):99-106. doi:10.1038/nrc1802 6- Brown DC, Gatter KC. Ki67 protein: The immaculate deception? Histopathology. 2002;40(1):2-11. doi:10.1046/j.13652559.2002.01343.x

7- Myoung H, Kim MJ, Lee JH, Ok YJ, Paeng JY, Yun PY. Correlation of proliferative markers (Ki-67 and PCNA) with survival and lymph node metastasis in oral squamous cell carcinoma: a clinical and histopathological analysis of 113 patients. Int J Oral Maxillofac Surg. 2006;35(11):1005-10. doi:10.1016/j.ijom.2006.07.016

8- Kidani K, Osaki M, Tamura T, Yamaga K, Shomori K, Ryoke K, et al. High expression of $\mathrm{EZH} 2$ is associated with tumor proliferation and prognosis in human oral squamous cell carcinomas. Oral Oncol. 2009;45(1):39-46. doi:10.1016/j.oraloncology.2008.03.016 
9- Jing $Y$, Zhou Q, Zhu H, Zhang $Y$, Song $Y$, Zhang $X$, et al. Ki-67 is an independent prognostic marker for the recurrence and relapse of oral squamous cell carcinoma. Oncol Lett. 2019;17(1):974-80. doi:10.3892/ol.2018.9647

10- Xie S, Liu Y, Qiao X, Hua RX, Wang K, Shan XF, et al. What is the prognostic significance of $\mathrm{Ki}-67$ positivity in oral squamous cell carcinoma? J Cancer. 2016;7(7):758-67. doi:10.7150/jca.14214 11- Gadbail AR, Korde S, Chaudhary MS, Sarode SC, Gondivkar SM, Dande R, et al. Ki67, CD105, and a-SMA expression supports biological distinctness of oral squamous cell carcinoma arising in the background of oral submucous fibrosis. Asian Pac J Cancer Prev. 2020;21(7):206774. doi:10.31557/APJCP.2020.21.7.2067

12- Gadbail AR, Chaudhary MS, Sarode SC, Gondivkar SM, Belekar L, Mankar-Gadbail MP, et al. Ki67, CD105 and $\alpha$ smooth muscle actin expression in disease progression model of oral submucous fibrosis. J Investig Clin Dent. 2019;10(4):e12443. doi:10.1111/jicd.12443 13- American Joint Committee on Cancer. Lip and oral cavity. In: Greene FL, Page DL, Fleming ID, Fritz AG, Balch CM, Haller DG, et al . AJCC Cancer staging manual. $6^{\text {th }}$ ed. New York: Springer; 2002. p. 23-32. doi:10.1007/978-1-4757-3656-4_3

14- Dissanayake $U$, Johnson NW, Warnakulasuriya KA. Comparison of cell proliferation in the centre and advancing fronts of oral squamous cell carcinomas using Ki-67 index. Cell Prolif. 2003;36(5):255-sdfa64. doi:10.1046/j.1365-2184.2003.00282.x

15- Gadbail AR, Chaudhary MS, Sarode SC, Gawande M, Korde S, Tekade SA, et al. Ki67, CD105, and a-SMA expressions better relate the binary oral epithelial dysplasia grading system of World Health Organization. J Oral Pathol Med. 2017;46(10):921-7. doi:10.1111/ jop. 12612

16- Siegel RL, Miller KD, Jemal A. Cancer statistics, 2015. CA Cancer J Clin. 2015;65(1):5-29. doi:10.3322/caac.21254

17- Monteiro LS, Amaral JB, Vizcaíno JR, Lopes CA, Torres FO. A clinicalpathological and survival study of oral squamous cell carcinomas from a population of the north of Portugal. Med Oral Patol Oral Cir Bucal. 2014;19(2):120-6. doi:10.4317/medoral.19090

18- Rodrigues RM, Bernardo VG, Silva SD, Camisasca DR, Faria PA, Dias $\mathrm{FL}$, et al. How pathological criteria can impact prognosis of tongue and floor of the mouth squamous cell carcinoma. J Appl Oral Sci. 2019;28:e20190198. doi: 10.1590/1678-7757-2019-0198.

19- Tomo S, Conrado S Neto, Collado FU, Sundefeld ML, Bernabé DG, Biasoli ÉR, et al. Head and neck squamous cell carcinoma in young patients: a 26-year clinicopathologic retrospective study in a Brazilian specialized center. Med Oral Patol Oral Cir Bucal. 2020;25(3):e416-24. doi: $10.4317 /$ medoral.23461.

20- Abrahão R, Perdomo S, Pinto LF, Nascimento de Carvalho F, Dias FL, Podestá JR, et al. InterCHANGE Group. Predictors of survival after head and neck squamous cell carcinoma in South America: the interCHANGE study. JCO Glob Oncol. 2020;6:486-99. doi: 10.1200/GO.20.00014. 21- Dourado MR, Miwa KY, Hamada GB, Paranaíba LM, SawazakiCalone Í, Domingueti CB, et al. Prognostication for oral squamous cell carcinoma patients based on the tumour-stroma ratio and tumour budding. Histopathology. 2020;76(6):906-18. doi: 10.1111/his.14070. 22- Lin NC, Hsu JT, Tsai KY. Survival and clinicopathological characteristics of different histological grades of oral cavity squamous cell carcinoma: A single-center retrospective study. PLoS One. 2020;15(8):e0238103. doi: 10.1371/journal.pone.0238103.

23- Li LT, Jiang G, Chen Q, Zheng JN. Ki67 is a promising molecular target in the diagnosis of cancer. Mol Med Rep. 2015;11(3):1566-72. doi:10.3892/mmr.2014.2914

24- Freudlsperger C, Rohleder SE, Reinert S, Hoffmann J. Predictive value of high $\mathrm{Ki}-67$ expression in stage $\mathrm{i}$ oral squamous cell carcinoma specimens after primary surgery. Head Neck. 2011;33(5):668-72. doi: $10.1002 /$ hed. 21502
25- Lopes VK, Jesus AS, Souza LL, Miyahara LA, Guimarães DM, et al. Ki-67 protein predicts survival in oral squamous carcinoma cells: an immunohistochemical study. Braz Oral Res. 2017;31:e66. doi:10.1590/1807-3107BOR-2017.vol31.0066

26- Sittel C, Ruiz S, Volling P, Kvasnicka HM, Jungehülsing M, Eckel HE. Prognostic significance of Ki-67 (MIB1), PCNA and p53 in cancer of the oropharynx and oral cavity. Oral Oncol. 1999;35(6):583-9. doi:10.1016/S1368-8375(99)00041-X

27- Brockton NT, Lohavanichbutr P, Enwere EK, Upton MP, Kornaga EN, Nakoneshny SC, et al. Impact of tumoral carbonic anhydrase IX and $\mathrm{Ki}-67$ expression on survival in oral squamous cell carcinoma patients. Oncol Lett. 2017;14(5):5434-42. doi:10.3892/ol.2017.6829

28- Coutinho-Camillo CM, Lourenço SV, Nishimoto IN, Kowalski LP, Soares FA. Nucleophosmin, p53, and Ki-67 expression patterns on an oral squamous cell carcinoma tissue microarray. Hum Pathol. 2010;41(8):1079-86. doi:10.1016/j.humpath.2009.12.010

29- Bettendorf O, Herrmann G. Prognostic relevance of $\mathrm{Ki}$ 67 antigen expression in 329 cases of oral squamous cell carcinoma. ORL J Otorhinolaryngol Relat Spec. 2002;64(3):200-5. doi:10.1159/000058025

30- Bova RJ, Quinn DI, Nankervis JS, Cole IE, Sheridan BF, Jensen MJ, et al. Cyclin D1 and p16INK4A expression predict reduced survival in carcinoma of the anterior tongue. Clin Cancer Res. 1999;5(10):2810-9. 31- Ahmad B, Asif M, Ali A, Jamal S, Khan MZ, Khadim MT. Expression of $\mathrm{Ki}-67$ and beta-catenin in pseudoepitheliomatous hyperplasia and squamous cell carcinoma in oral mucosal biopsies: an immunohistochemical study. Asian Pacific J Cancer Prev. 2020;21(1):157-61. doi:10.31557/APJCP.2020.21.1.157

32- Carlos De Vicente J, Herrero-Zapatero A, Fresno MF, López-Arranz JS. Expression of cyclin D1 and $\mathrm{Ki}-67$ in squamous cell carcinoma of the oral cavity: Clinicopathological and prognostic significance. Oral Oncol. 2002;38(3):301-8. doi:10.1016/S1368-8375(01)00060-4

33- Tumuluri V, Thomas GA, Fraser IS. Analysis of the Ki-67 antigen at the invasive tumour front of human oral squamous cell carcinoma. J Oral Pathol Med. 2002;31(10):598-604. doi:10.1034/j.16000714.2002.00042.x

34- Chandak AR, Gadbail AR, Chaudhary MS, Chandak SA, Wadhwani R. Actual proliferating index in oral squamous cell carcinoma and leukoplakia. J Investig Clin Dent. 2011;2(3):176-83. doi:10.1111/ j.2041-1626.2011.00057.x

35- Takkem A, Barakat C, Zakaraia S, Zaid K, Najmeh J, Ayoub M, et al. $\mathrm{Ki}-67$ prognostic value in different histological grades of oral epithelial dysplasia and oral squamous cell carcinoma. Asian Pacific J Cancer Prev. 2018;19(11):3279-86. doi:10.31557/APJCP.2018.19.11.3279

36- Cortegoso AV, Laureano NK, Silva AD, Danilevicz CK, Magnusson AS, Visioli $F$, et al. Cell proliferation markers at the invasive tumor front of oral squamous cell carcinoma: comparative analysis in relation to clinicopathological parameters of patients. J Appl Oral Sci. 2017;25(3):318-23. doi:10.1590/1678-7757-2016-0238

37- Matsumoto M, Komiyama K, Okaue M, Shimoyama Y, Iwakami K, Namaki $S$, et al. Predicting tumor metastasis in patients with oral cancer by means of the proliferation marker Ki67. J Oral Sci. 1999;41(2):53-6. doi: $10.2334 /$ josnusd.41.53

38- Nazar M, Naz I, Mahmood MK, Hashmi SN. Immunohistochemical expression of Cyclin D1 and $\mathrm{Ki}-67$ in primary and metastatic oral squamous cell carcinoma. Asian Pacific J Cancer Prev. 2020;21(1):3741. doi:10.31557/APJCP.2020.21.1.37 